\title{
A Mathematical Expression for Oxygen-induced Death in Dehydrated Bacteria
}

\author{
By C. S. COX, JEAN BAXTER AND B. J. MAIDMENT \\ Microbiological Research Establishment, Porton Down, \\ Nr Salisbury, Wiltshire
}

(Received 6 July 1972; revised 29 November 1972)

\begin{abstract}
SUMMARY
A mathematical expression for oxygen-induced death of dehydrated bacteria is reported. Data in the literature for Serratia marcescens $8 \mathrm{UK}$ were analysed and the expression describes viability changes over a range of $10^{4}$, oxygen concentration effects over a range of 400 and the effect of time up to $3 \mathrm{~h}$. The expression should apply to the oxygen-induced death of other dehydrated bacteria.
\end{abstract}

\section{INTRODUCTION}

A bacteriostatic action of hyperbaric oxygen has been reported for suspensions of bacteria in water (Haugaard, I968), whereas the bactericidal action of oxygen requires the absence of liquid water, as indicated below. Several investigators have reported that freeze-dried bacteria are killed even by hypobaric oxygen (Rogers, 19I4; Benedict et al. 196I; Lion \& Bergmann, 1961; Dewald, 1966; Cox \& Heckly, 1973). Also, bacteria in aerosols at low relative humidity (r.h.) are killed by oxygen (Ferry, Brown \& Damon, I958; Hess, I965; Cox, 1966, 1968, 1970a, 1970b; Cox \& Baldwin, 1966, I967; Benbough, 1967, 1969; Webb, 1967, I969; Cox, Bondurant \& Hatch, I97I). Recently, frozen bacteria exposed to oxygen have been shown to lose viability (Schwartz, 1970, 1971; Cox \& Heckly, 1972).

In most of the above work the kinetics of oxygen-induced death were not understood. Dewald (1966) found an empirical relationship describing the effect of time and oxygen concentration upon loss of survival of Serratia marcescens 8UK. However, this relationship did not fit the data of Cox \& Heckly (1972) or that of Hess (1965). The present paper reports a mathematical expression which does fit data in the literature concerning oxygen-induced loss of viability of dehydrated bacteria as a function of storage time and oxygen concentration.

\section{EXPERIMENTAL DATA}

Of the reports of oxygen-induced death of bacteria (see Introduction for references) only those of Hess (1965), Dewald (1966) and Cox \& Heckly (1973) contain sufficiently detailed data on effects of oxygen concentration (based on partial pressures) and time to permit mathematical analysis.

The data of Hess (1965) were obtained in the aerosol phase at $40 \%$ r.h., unlike those of Dewald (I966) and Cox \& Heckly (1973) which were obtained in the freeze-dried state at $0 \%$ r.h. The data of Dewald (1966) might have a large experimental error because in the text he indicated that

$$
-\ln \left(\frac{N}{N_{0}}\right)=k\left[\mathrm{O}_{2}\right]^{\frac{1}{3}} t^{\frac{1}{2}}
$$




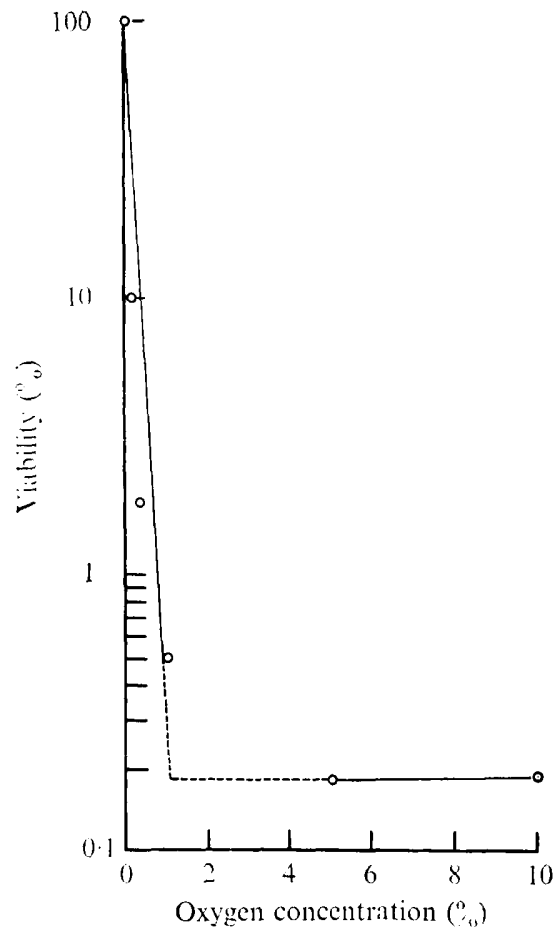

Fig. I. Viability $(\%)$ versus oxygen concentration $(\%)$ for oxygen-induced death of Serratia marcescens $8 \mathrm{UK} / 2$, stored under oxygen for 3 h. Data of Cox \& Heckly (I973).

Whereas in his Fig. 6 he showed that the viability data were of the form

$$
-\ln \left(\frac{N}{N_{0}}\right)_{t}=k \ln \left[\mathrm{O}_{2}\right]+K
$$

For the work of Cox \& Heckly (1973) two sources of Serratia marcescens 8uK were used (labelled $8 \mathrm{UK} / \mathrm{I}$ and $8 \mathrm{UK} / 2$ ), because even though the original strain of $8 \mathrm{UK}$ came from Fort Detrick, Maryland, U.S.A., the subsequent histories of strains $8 \mathrm{UK} / \mathrm{I}$ and $8 \mathrm{UK} / 2$ were different and these gave rise to populations having different survival characteristics. One of the difficulties with their set of experimental data was that unlike strain $8 \mathrm{UK} / 2$, strain $8 \mathrm{UK} / \mathrm{I}$ was not completely stable in the absence of oxygen. For analysis, the experimental data obtained with $8 \mathrm{UK} / \mathrm{I}$ had to be corrected for this effect. Moreover, since the kinetics of viability loss in the absence of oxygen are not completely understood, this correction had to be empirical in nature and was based on taking ratios of survival in the presence of oxygen to survival in a vacuum.

The data obtained by Hess (1965), Dewald (1966) and Cox \& Heckly (I973) all show that, as the oxygen concentration increased, the kinetics with respect to oxygen concentration were first order at low oxygen concentration (i.e. logarithm of the viability at a given storage time was directly proportional to oxygen concentration) and zero order at high oxygen concentration (i.e. logarithm of the viability at a given storage time was independent of oxygen concentration). This phenomenon is indicated in Fig. I for data obtained by Cox \& Heckly (1973) with Serratia marcescens $8 \mathrm{UK} / 2$ at $3 \mathrm{~h}$ storage time.

The relationship between viability and storage time is more complex in that the slope of the 
curve of log viability versus time is constant at low oxygen concentrations (Hess, 1965), while at higher oxygen concentrations the slope of the curve decreases with time (Hess, 1965; Dewald, 1966; Cox \& Heckly, 1973).

\section{MATHEMATICAL ANALYSIS}

In an attempt to derive a mathematical expression which would describe all of the above observations, the analogy with the enzyme kinetic relationship between velocity of reaction and substrate concentration was used to account for the observed effects of oxygen concentration upon viability.

It was assumed that a complex formed between oxygen and a carrier $X$, i.e.

$$
X+\mathrm{O}_{2} \underset{\kappa_{x}}{\rightleftharpoons} X \mathrm{O}_{2}
$$

and that this complex then caused a substance, $A$, to become oxidized without the formation of a ternary complex, i.e.

$$
X \mathrm{O}_{2}+A \stackrel{k}{\longrightarrow} A \mathrm{O}_{2}+X
$$

It is postulated that the substance $A$ is essential for bacteria to be viable and that in its oxidized state, $A \mathrm{O}_{2}$, it is biologically inactive.

The differential equations describing the reactions listed above can only be integrated numerically. However, if $\mathrm{d}\left[\mathrm{XO}_{2}\right] / \mathrm{d} t=0$, the differential equations can be analytically integrated to give equation (3), provided that $\mathrm{d}\left[\mathrm{O}_{2}\right] / \mathrm{d} t=0$, as found in practice (Cox, unpublished data; Dewald, 1966). Analogue computer studies indicated that for oxygen-induced death $\mathrm{d}\left[\mathrm{XO}_{2}\right] / \mathrm{d} t=0$, in terms of the above mechanism.

therefore

$$
\ln \frac{[A]_{0}}{[A]}=\frac{k[X]_{0}\left[\mathrm{O}_{2}\right] t}{K_{x}+\left[\mathrm{O}_{2}\right]}
$$

where,

$$
\begin{aligned}
& {[A]_{0}=\text { concentration of } A \text { at } t=\text { time }=0,} \\
& {[A]=\text { concentration of } A \text { at } t=t(\mathrm{~h}),} \\
& {[X]_{0}=\text { concentration of } X,} \\
& {\left[\mathrm{O}_{2}\right]=\text { concentration of oxygen }(\%),} \\
& K_{x}=\text { equilibrium constant }(\%), \\
& k \quad=\text { velocity constant for conversion of } A \text { to } A \mathrm{O}_{2} .
\end{aligned}
$$

According to the postulate, viability must be related to the concentration term $[A]$. Equation (3) shows that $-\ln [A]$ is proportional to $t$, yet the slope of the curve of $\log$ viability versus time decreases with time. This is accounted for because the relationship between viability and $[A]$ is of the form,

Given the statements,

$$
\ln V_{i}=K_{1}[A]+K_{2} .
$$

and

$$
\begin{aligned}
P_{D} N_{L} & =-\delta N_{L} \\
P_{D} & =-K_{\mathbf{1}} \delta[A]
\end{aligned}
$$

where

$$
\begin{aligned}
& P_{D}=\text { probability that a bacterium will die } \\
& N_{L}=\text { number of live bacteria }
\end{aligned}
$$


it follows that,

$$
\frac{\delta N_{L}}{\delta[A]}=K_{1} N_{L}
$$

i.e.

where,

$$
\frac{\delta V_{i}}{\delta[A]}=K_{1} V_{i}
$$

and

$$
V_{i}=\text { viability }=\frac{N_{L}}{N_{L}+N_{D}}
$$

$$
N_{D}=\text { number of dead bacteria. }
$$

Hence by integration,

$$
\ln V_{i}=K_{1}[A]+K_{2} .
$$

Combining equations (3) and (4) gives,

$$
\ln V_{i}=K_{1}[A]_{0}\left\{\exp \left[-\frac{k[X]_{0}\left[\mathrm{O}_{2}\right] t}{K_{x}+\left[\mathrm{O}_{2}\right]}\right]-\mathrm{I}\right\}+\ln 100 .
$$

It is assumed that in a population of bacteria there is a distribution of values of the concentration terms $[A]$ and $[X]$, and that $[A]_{0},[A]$ and $[X]_{0}$ represent some average value for the concentrations of species $A$ and $X$. If this were not so, then it is difficult to see why all dehydrated bacteria exposed to oxygen do not all die at the same time.

It is possible that equations other than (5) could be derived to account for oxygen-induced loss of viability. However, if viability is related to the concentration of some species $A$, then equation (4) applies. Also, the observation that the effect of increasing oxygen concentration approaches a definite limit has to be explained. Provided that these two statements are accepted, then a reaction mechanism differing fundamentally from that given in equations (I) and (2) is by no means obvious.

An ICL 1905 computer was used in the analyses. The programme determined the values of $K_{1}[A]_{0}, k[X]_{0}$ and $K_{x}$ by minimizing (using the method of Rosenbrock, 1960) the residual sum of squares of values obtained when log predicted viability was compared with log observed viability. It was assumed that this method gave the best fit between observed and predicted viabilities.

\section{RESULTS}

The results for each set of data are presented in Fig. 2 to 5 and the values of the parameters are given in Table $\mathrm{I}$. The following points may be noted:

(i) the similar effects of 5 and $10 \%$ oxygen are accurately accounted for (Fig. 2);

(ii) in Fig. 4 viabilities of the order of $0.01 \%$ were obtained, i.e. equation (5) accounts for a reaction which attains $99.99 \%$ of completion;

(iii) in general, equation (5) accurately describes the effects of oxygen concentration and time upon oxygen-induced death of Serratia marcescens $8 \mathrm{UK}$.

\section{DISCUSSION}

The analyses indicate that the available data for oxygen-induced death of Serratia marcescens $8 \mathrm{UK}$ can be described in terms of equation (5). But, such a finding is, of course, no proof that the mechanism on which this equation is based is the one occurring in nature. 


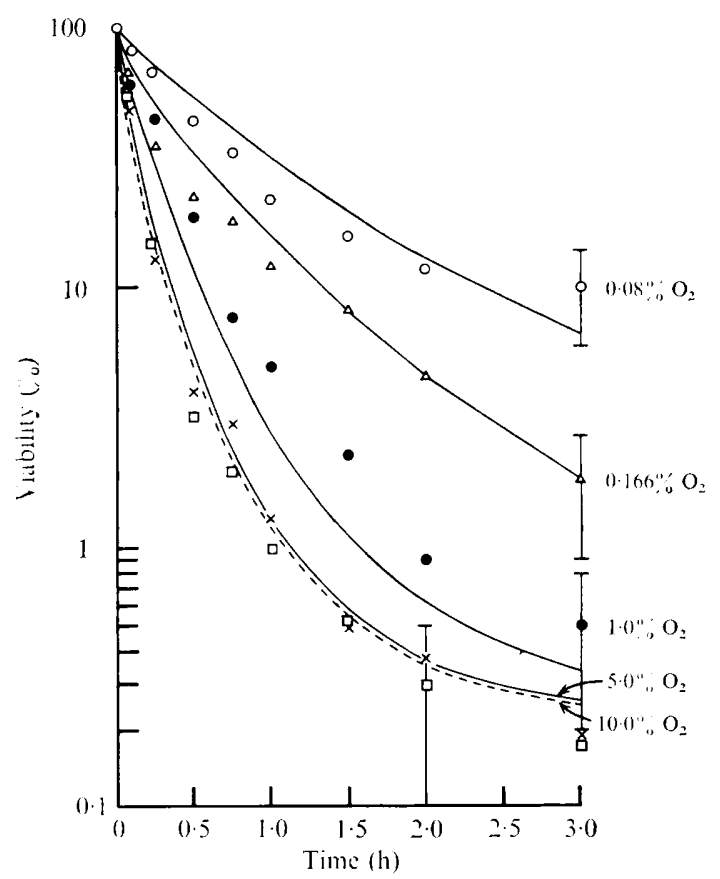

Fig. 2

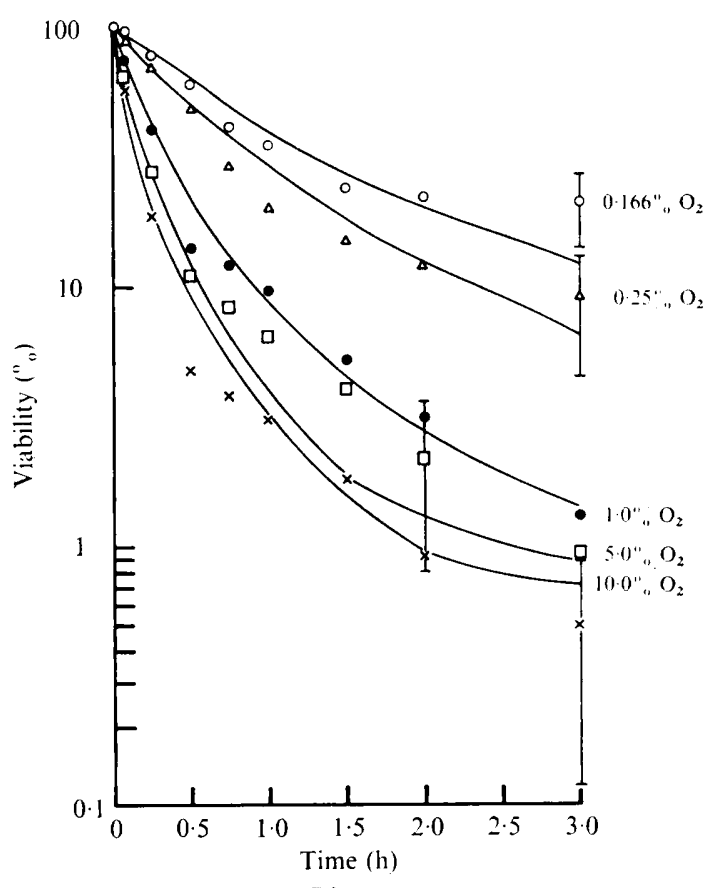

Fig. 3

Fig. 2. Comparison of experimental and theoretical values of $\%$ viability of Serratia marcescens 8UK $/ 2$ as a function of oxygen concentration $(\%)$ and time (h). Points, experimental data; lines, calculated. Data of Cox \& Heckly (1973).

Fig. 3. Comparison of experimental and theoretical values of $\%$ viability of Serratia marcescens $8 \mathrm{UK} / \mathrm{I}$ as a function of oxygen concentration $(\%)$ and time (h). Points, experimental data; lines, calculated. Data of Cox \& Heckly (1973).

The variation in the value of $K_{x}$ indicates that the ability of species $X$ to combine with oxygen was different for the sets of data analysed. A small value of $K_{x}$ indicates a high affinity between species $X$ and oxygen. The values of $K_{1}[A]_{0}$ were somewhat similar for the data analysed, and indicate that a large value of $K_{1}[A]_{0}$ is indicative of sensitivity to oxygen. The values of $k[X]_{0}$ were virtually the same for data obtained at $0 \%$ r.h. (Fig. 2 to 4 ). The results for the studies at $40 \%$ r.h. (Fig. 5) suggest that the effect of r.h. upon oxygen-induced death might be through the effect of humidity upon $k$.

The expressions unfortunately cannot indicate the nature of species $A$ or $X$, although lipids, $-\mathrm{SH}$ groups and metal ions might be involved (Haugaard, 1968). Experimental data concerning DNA synthesis showed that this reaction was not inactivated by oxygen (Benbough, 1967; Cox et al. 197I). Also, the ability to metabolize oxygen was the same for Escherichia coli aerosolized into air and into nitrogen, i.e. there was no effect on oxygen uptake caused by loss of viability induced by oxygen (Cox et al. 1971). These results in conjunction with those of Cox \& Baldwin (1966), which showed that E. coli B killed by oxygen can still reproduce phage $T_{7}$, indicate that the toxic action of oxygen could cause inhibition of cell wall synthesis and/or cell division. Such a mechanism is entirely consistent with the finding that Semliki Forest virus and phage $\varnothing X 174$ (Cox, unpublished data), poliovirus (de Jong \& Winkler, 1968) and Semliki Forest virus, Langat virus, phage T7 and poliovirus (Benbough, I97I), are not inactivated in the aerosol form by oxygen. 


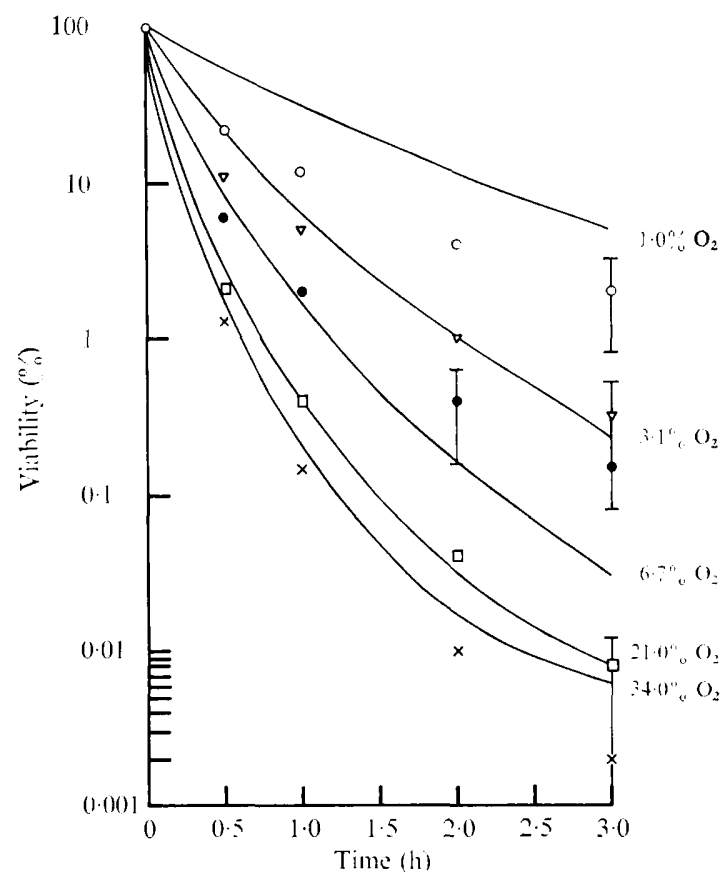

Fig. 4

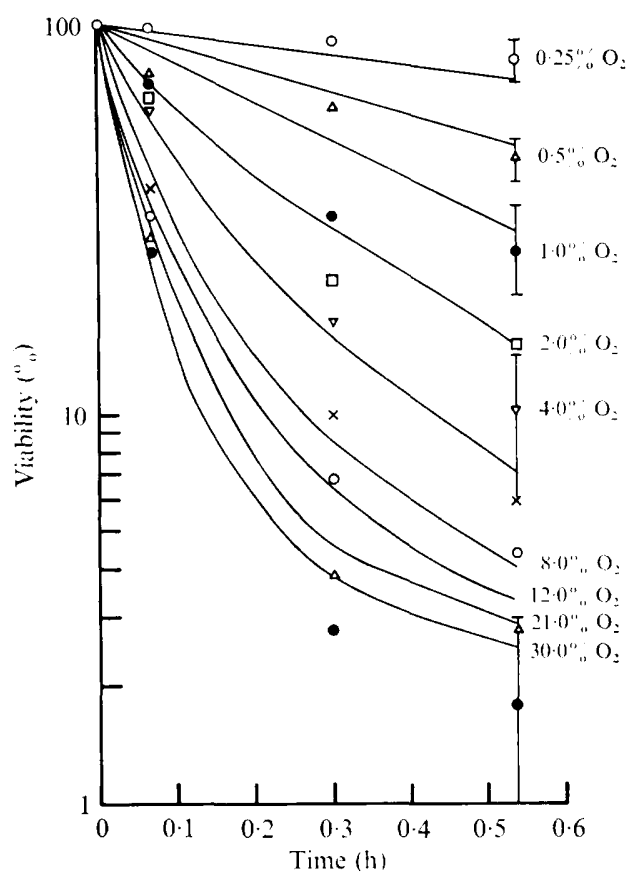

Fig. 5

Fig. 4. Comparison of experimental and theoretical values of $\%$ viability of Serratia marcescens $8 \mathrm{UK}$ as a function of oxygen concentration $(\%)$ and time (h). Points, experimental data; lines, calculated. Data of Dewald (1966).

Fig. 5. Comparison of experimental and theoretical values of $\%$ viability of Serratia marcescens $8 \mathrm{UK}$ as a function of oxygen concentration $(\%)$ and time (h). Points, experimental data; lines, calculated. Data of Hess (1965).

Table I. Values of the constants derived from experimental data for oxygen-induced death of Serratia marcescens

$\begin{array}{lccc}\text { Data and strain } & \begin{array}{c}K_{1}[A]_{\mathrm{o}} \\ \text { (unitless) }\end{array} & \begin{array}{c}k[X]_{0} \\ \left(\mathrm{~h}^{-1}\right)\end{array} & \begin{array}{c}K_{x} \\ (\%)\end{array} \\ \text { \& Heckly (1973) 8UK/2 } & 6 \cdot \mathrm{I} & \mathrm{I} \cdot 3 & 0 \cdot 46 \\ \text { \& Heckly (1973) 8UK/I } & 4 \cdot 9 & \mathrm{I} \cdot 4 & \mathrm{I} \cdot 0 \\ \text { vald (1966) 8UK } & 10 & \mathrm{I} \cdot 2 & 8 \cdot 7 \\ \text { s (1965) 8UK } & 3 \cdot 7 & 10 & 13\end{array}$

Other experimental data, such as the effect of growth conditions in a chemostat upon subsequent survival of bacteria, might indicate moieties involved in loss of survival induced by oxygen, because the composition of bacteria can be altered, for example, by fixing the dilution rate and varying the growth temperature. The use of the heavy isotope of oxygen also might indicate the nature of species $X$ and possibly $A$.

In conclusion, the equations discussed here can describe observed viability changes over a range of $10^{4}$, oxygen concentration effects over a range of 400 and the influence of time up to $3 \mathrm{~h}$. The equations so far have only been applied to Serratia marcescens $8 \mathrm{UK}$. The possibility of more general application requires survival data for other bacteria.

The authors thank Dr P. Watts for carrying out the analogue computer studies. 


\section{REFERENCES}

Benbough, J. E. (1967). Death mechanisms in airborne Escherichia coli. Journal of General Microbiology 47, 325-333.

Benbough, J. E. (1969). Factors affecting the toxicity of oxygen towards airborne coliform bacteria. Journal of General Microbiology 56, 24 I-250.

Benbough, J. E. (197I). Some factors affecting the survival of airborne viruses. Journal of General Virology Io, 209-220.

Benedict, R. G., Sharpe, E. S., Corman, J., Meyers, G. B., Baer, E. F., Hall, H. H. \& Jackson, R. W. (I96I). Preservation of micro-organisms by freeze-drying. II. The destructive action of oxygen. Additional stabilizers for Serratia marcescens. Experiments with other organisms. Applied Microbiology 9, 256-262.

Cox, C. S. (1966). The survival of Escherichia coli atomized into air and into nitrogen from distilled water and from solutions of protecting agents, as a function of relative humidity. Journal of General Microbiology 43, 383-399.

Cox, C. S. (1968). The aerosol survival and cause of death of Escherichia coli K I 2. Journal of General Microbiology 54, I 69-175.

Cox, C. S. (1970a). Aerosol survival of Escherichia coli B disseminated from the dry state. Applied Microbiology 19, 604-607.

Cox, C. S. $(1970 b)$. Aerosol survival of Pasteurella tularensis disseminated from the wet and dry state. Applied Microbiology 21, 482-486.

Cox, C. S. \& Baldwin, F. (I966). The use of phage to study causes of loss of viability of Escherichia coli in aerosols. Journal of General Microbiology 44, 15-22.

Cox, C. S. \& Baldwin, F. (1967). The toxic effect of oxygen upon aerosol survival of Escherichia coli B. Journal of General Microbiology 49, I I5-1 I 7.

Cox, C. S., Bondurant, M. C. \& Hatch, M. T. (I97I). Effects of oxygen on aerosol survival of radiation sensitive and resistant strains of Escherichia coli B. Journal of Hygiene 69, 66I-672.

Cox, C. S. \& Heckly, R. J. (1973). Effects of oxygen upon freeze-dried and freeze-thawed bacteria: viability and free radical studies. Canadian Journal of Microbiology (in the Press).

Dewald, R. R. (1966). Kinetic studies on the destructive action of oxygen on lyophilized Serratia marcescens. Applied Microbiology 14, 568-572.

Ferry, R. M., Brown, W. F. \& Damon, E. B. (1958). Studies of the loss of viability of bacterial aerosols. III. Factors affecting death rates of certain non-pathogens. Journal of Hygiene 56, 389-403.

Haugaard, N. (1968). Cellular mechanisms of oxygen toxicity. Physiological Reviews 48, 31 I-373.

Hess, G. E. (1965). Effects of oxygen on aerosolized Serratia marcescens. Applied Microbiology 13, $781-787$.

DE JONG, J. C. \& WinkLeR, K. C. (1968). The inactivation of poliovirus in aerosols. Journal of Hygiene 66, $557-565$.

Lion, M. B. \& Bergmann, E. D. (196I). The effect of oxygen on freeze-dried Escherichia coli. Journal of General Microbiology 24, I9I-200.

Rogers, L. A. (1914). The preparation of dried cultures. Journal of Infectious Diseases 14, IOO-I 23.

Rosenbrock, H. H. (1960). An automatic method for finding the greatest or least value of a function. Computer Journal 3, 175-184.

Schwartz, H. M. ( 1970 ). Effect of oxygen on freezing damage. I. Effect on survival of Escherichia coli $\mathrm{B} / \mathrm{r}$ and Escherichia coli $\mathrm{B}_{\mathrm{s}-1}$. Cryobiology 6, 546-55I.

Schwartz, H. M. (197I). Effect of oxygen on freezing damage. II. Physical-chemical effects. Cryobiology 8 , $225-264$.

WebB, S. J. (1967). The influence of oxygen and inositol on survival of semi-dried organisms. Canadian Journal of Microbiology 13, 733-742.

WebB, S. J. (1969). The effects of oxygen on the possible repair of dehydration damage by Escherichia coli. Journal of General Microbiology 58, 317-326. 